\title{
How old are (pet) dog breeds?
}

\author{
Christoph Jung $^{1 *}$, Daniela Pörtl²
}

\section{Abstract}

Dogs are our Pets. Everybody knows dog breeds, at least we are familiar with common breads. A dog is often understood only as a specimen of a breed or a mongrel of several breeds. Some scholars argue that dog breeds would be created as an artificial product starting 150 years ago in the Victorian era. The original dog would be an uniform dog type called "village dog", hanging around human settlements while scavenging human waste and faeces. Our review of the literature suggests, that there is limited data and evidence relevant to the evolution and history of dog breeds and dog breeding in general to support this theory. In our article we will examine further data and present additional evidence. We found many records in history, archaeology and genetics pointing out that dog breeds have a long history likely starting in prehistoric times or at least in antiquity. Dog breeds are not static. We should understand dog breeds as steadily evolving populations in changing ecologies - like each other species. Dogs' ecological positions were defined primarily by humans. We are able to identify and clearly differentiate dogs according to their breeds; each breed is fitting to its special niches. We are using dogs' different traits for thousands of years. Dogs always have and continue to have their jobs related to hunting-, herding-, sledding-partners or as pets. Consequently, dogs have been moulded to fit to each job and accordingly. In the long run, dogs evolved through their changing jobs and according to continually evolving human civilisation. Breeds have not been simply created. Breeds did not derive artificially during some decades in the Victorian era. Victorian dog breeding culture only switched the focus from the behaviour to the appearance and that mainly with regard to fashion dogs. Even standardized modern purebred dogs on the official shows are continuously changing their traits and appearance following human fashions. Dog breeds may be understood as a reflection of human culture. Understanding the history of dog breeds is helpful for a better understanding of our dogs, the human-dog bonding and ourselves.

Pet Behaviour Science | 2019, Vol.7, 29 - 37

DOI: $10.21071 / p b s . v 0 i 7.11494$

Christoph Jung $^{1 *}$, Daniela Pörtl

1.Petwatch

Review

2. Psychiatric department, SaaleUnstrut Klinikum, teaching hospital Leipzig and Jena Universities,

Naumburg

\section{* Email:}

jung@petwatch.de

$$
\text { Naumburg }
$$

Germany

Keywords:

dog; evolution; breed; coevolution; human-dogbonding

\section{HIGHLIGHTS}

- Dog breeds and even pet dog breeds have a long history

- Most of today's pet dog breeds were derived from working breeds

- Dog breeds may be understood as a reflection of human culture

- We should understand dog breeds as continuously evolving populations in changing ecologies

- Understanding the history of breeds is crucial for a better understanding of dogs' behavior and to improve human-dog-bonding 


\section{Introduction}

Over 350 dog breeds are described all over the world. They are recognized by at least one of the big international Kennel Clubs. People love mongrels or their special breed. Pet Dog breeding has become a big business for over 100 years. However, we do not really know very much about the origin and history of dog breeding and dog breeds.

Some scholars spread the idea that dog breeds would be a relative new phenomenon in the evolution and history of dogs and humankind. They declare, that the era of dog breeding at first started in the Victorian Britain, 150 to 200 years ago (Coppinger and Coppinger 2003, 2016; Lord et al. 2013; Hekman 2018) as simply an invention of this era (Worboys et al. 2018). They argue that village dogs would have been the original dogs, not living together with people but only nearby humans, scavenging on human waste. Today's breeds would have been shaped due to artificial selection from village dogs imposed by fanciers during the last less than 200 years.

Our aim is to shed a light on the history of dog breeding and consequently human history and evolution as well. Dogs are surely the first non-human animals living with us for at least 15.000 years (Thalmann et al. 2013; Botigué et al. 2017). We think it is important to study the evolution of dogs as a part of our own evolution and human culture. The question we would like to address and analyse: is it the nature of dogs hanging around human settlements as scavengers like most scholars and media argue? Alternatively, was the relationship between dogs and humans a partnership? Were dogs and humans living and "working" together already in ancient times (Brewer et al. 2001; Pörtl and Jung 2017; Jung and Pörtl 2018; Germonpré et al. 2018)?

If so, dog breeds must have evolved a long time ago. We recognize that dog breeds evolved as a manifestation of optimized traits for their diverse jobs catering to humans, including hunting-, herding-, guarding-, sledding-partners or simply as pets. Assigned tasks and jobs were, however, changing. Dogs and people have shaped each other and impacted on each other permanently during their evolution and history. From the Chihuahua to the Great Dane, dogs have been separated in breeds to fit to their different jobs. Thus, they are quite different in appearance and behaviour. Nevertheless, all dogs belong to exactly one species (Canis familiaris) or sub-species (Canis lupus familiaris). Belonging to one species only the plant species cabbage shows so extensive different shapes like dogs do. Can this be the fast result of diversification during only the last 150 to 200 years based on an uniform "original" dog type called village dog? Can it be an artificial event? We find thousands of titles describing single pet dog breeds and their history in our book stores. Quite all are written by breeders or fanciers of the described. Recent breed monographs trend to idealize their special breed, often appearing like tales for marketing purposes. They are not suitable for an answer nor as a source of science.

\section{Methods}

We adopted a broad multi-disciplinary approach including archaeology, paleo genetics, genetics and history. We investigated studies and ancient literature beginning with Xenophon and Aristotle and ending with a lot of dog books from the Victorian era. Interestingly Charles Darwin himself provides many hints and evidence for better understanding the nature and the history of dog breeds.

\section{Results}

We found evidence towards the existence of a first prehistoric dog breeds specializing in polar bear hunting and also other breeds specializing in dog sledding. This research encompasses a time period of 9000 years (Pitulko and Kasparov 2017). Ten fossilized dogs and a wooden sled were found on Zhokhov Island in the far north of Siberia. The dogs surely could be separated in two types, seven appeared like a today's Siberian husky, and three like a today's Greenland dog. The authors assume, that "it can be hypothesized that sled dog teams might have been used in Siberia as early as 15,000 years ago." Since the beginning of the Neolithic period we found growing evidence for dogs as specialized working partners for hunting, herding, sledding, guarding in many regions 
(Guagnin et al. 2018; Perri 2016; Jung 2011a). We know cave paintings and rock art from Northern-Africa or the Arabian Peninsula 9 to 10,000 years ago showing man and dog hunting or herding together (Guagnin et al. 2018; Coulson and Campbell 2001; Holl 2004).

We have evidence for the development of specialized breeds at least starting during the first great civilizations like Egypt, Mesopotamia and Greece (Brewer et al. 2001). The ancient Egyptians had been dog-lovers and bred at least ten documented breeds. It is remarkably that these breeds stood over all dynasties quite constantly, which means over 3,000 years (Brewer et al. 2001; Janssen and Janssen 1999). About 2,350 years before present (bp), the great Greek philosopher and scientist Aristotle, named the founder of Zoology, described seven dog breeds among them the Maltese as a pet dog breed. Aristotle gave hints how to feed and how to breed. "Of dogs there are several breeds. Of these the Laconian hound of either sex is fit for breeding purposes when eight months old."(Aristotle 2011, part 20). Already 100 years before, another Greek, Xenophon, had published his book titled "Cynegeticus" about hunting with dogs (Xenophon 2017). We can understand this book as the first written collection of breed-standards with detailed dog breeding instructions. That means intentional dog breeding in ancestry.

"Cave Canem" - it was common practice in ancient Rome indicating that dogs guarded house and yard. That is not the typical job for a stray or village dog. The Greek geographer Strabo describes 2,200 years bp sophisticated dogs from the British isles: "Britain produces hunting dogs with keen senses. The Celts use these as their domestic dogs for war purposes." (Strabo 2016) The Roman geographer Oppianus deepens this report and describes the British dogs as extremely strong and courageous fighters who could take on bulls (Oppianus 2012). The Germanic peoples compiled one article in their law, one from 22 articles, specially dedicated to dogs (Lex Baiuvariorum 2016). Their law described eleven dog breeds. A good "Leiti-hund" (like today's Bloodhound) had the legally based value of a horse.

In 1868 Charles Darwin summarized the recent evolution of dog breeding: "As several breeds of the dog have been slightly but sensibly modified within so short a period as the last one or two centuries, by the selection of the best individuals, modified in many cases by crosses with other breeds; and as we shall hereafter see that the breeding of dogs was attended to in ancient times, as it still is by savages, we may conclude that we have in selection, even if only occasionally practiced, a potent means of modification." (Darwin 1868, p. 43)

Intentional breeding is well documented from the Middle Age to the Victorian era mainly concerning hunting and companion dogs (Russell 2018). It was a privilege of aristocracy to breed hunting dogs. In the Middle Age, around 1387, the French Count Gaston Fébus wrote a book about hunting in which the different types of hunting dogs, their use, their training, ailments and care are described in detail (Klemettilä 2015). Royals, aristocrats, and large landowners were competing for the best-specialized hunting dogs for each hunting tasks. Thus, the great majority of dog breeds were - and still are - sophisticated breeds, specialized in one hunting profession, for example Greyhounds for hounding game, Beagles or Foxhounds as pack hounds for fox hunts, Pointers to find and point out the den of birds and hares, Dachshunds for hunting the badger out of his hole. The aristocratic breeding farms (in Germany called "Jägerhöfe") were working very professionally with standards, pedigrees and stud books. Lord Orford, was the Founder of the first ever Coursing Club, Swaffham Coursing Society in 1776 . He was respected as a very systematically working greyhound breeder, well documented - not only - by Charles Darwin (Darwin 1860; Russell 2018).

Not only hunting dogs have been bred intentionally for hundreds and thousands of years. Interestingly, several pet dog breeds have a long and well documented breeding history. The Maltese dog is recognised since Aristotle. The pug or the Blenheim spaniel were several times cited by Comte de Buffon (2009) and Charles Darwin (Darwin 1860, 1868). Konrad Gessner (1551) and John Caius (1570) described 21 British dog breeds in "De Canibus Britannicis" (Gessner 2008; Caius 2018). Comte de Buffon (2009), the great French naturalist, mentioned 30 races in his "Histoire naturelle" (1753 to 1767). Georges Cuvier, called the Founder of modern Zoology, mentioned in 1817 breeds like Bulldog, 
Greyhound, Pug, Spaniel, Barbet, Terriers, Pointer, Great Dane (Cuvier 2012).

In 1846 William Youatt described 31 breeds, varieties and crosses (Youatt 2015). He noted basic breeding instructions and wrote "It is probable that all dogs sprang from one common source, but climate, food, and cross-breeding caused variations of form, which suggested particular uses; and these being either designedly or accidentally perpetuated, the various breeds of dogs thus arose." John Henry Walsh, called "Stonehenge", described 66 dog breeds (36 hunting, 15 pet) and six cross-breeds (Walsh 2009). The Austrian Zoologists Leopold Fitzinger (2017) described 134 breeds and its varieties (among them 35 hound and 35 hunting breeds) and furthermore crosses of them in his report for the Imperial Austrian Academia in 1867. H.D. Richardson (2018) described 86 dog breeds very comprehensively along with illustrations; among them six pet dog breeds and furthermore nine mongrels among them the Bull-terrier; the latter became an official breed in 1936 (AKC). He also decribed basic dog breeding instructions (1857). Both, Charles Darwin and Richardson were documenting in detail and over seven generations the attempts to improve the braveness of Greyhounds by crossbreeding them with Bulldogs. In
1859, Stonehenge mentioned that a Greyhound pedigree should record 20 generations (Walsh 2009). The dog breeds, Charles Darwin and others were describing explicitly and verbatim addressed as "breeds" or "races", had never been "land races" or "village dogs".

Dog breeds were accurately described long before the Kennel Club was established in 1873. Darwin and the naturalists of the mid 19th century strictly differentiated between mongrels and breed dogs and were discussing the effects of crossbreeding. This denotes the existence of breeds. Consequently, we may hypothesize that intentional dog breeding has a very long tradition in human civilization, and did not suddenly start with modern dog breeding organizations. Nevertheless, the Victorian era set a caesura in the history of dog breeding. Corresponding to basic changes in economy (Industrial Revolution), society (Urbanization) and further changes pertinent to human lifestyle, for example, hunting practices, the tasks for dogs changed accordingly.

Still, hunting dogs have always had the broadest diversity pertinent to dog breeds; until to date the majority of dog breeds belongs to this group. About 60
Figure 1. 140 years Pug evolution under the same standard

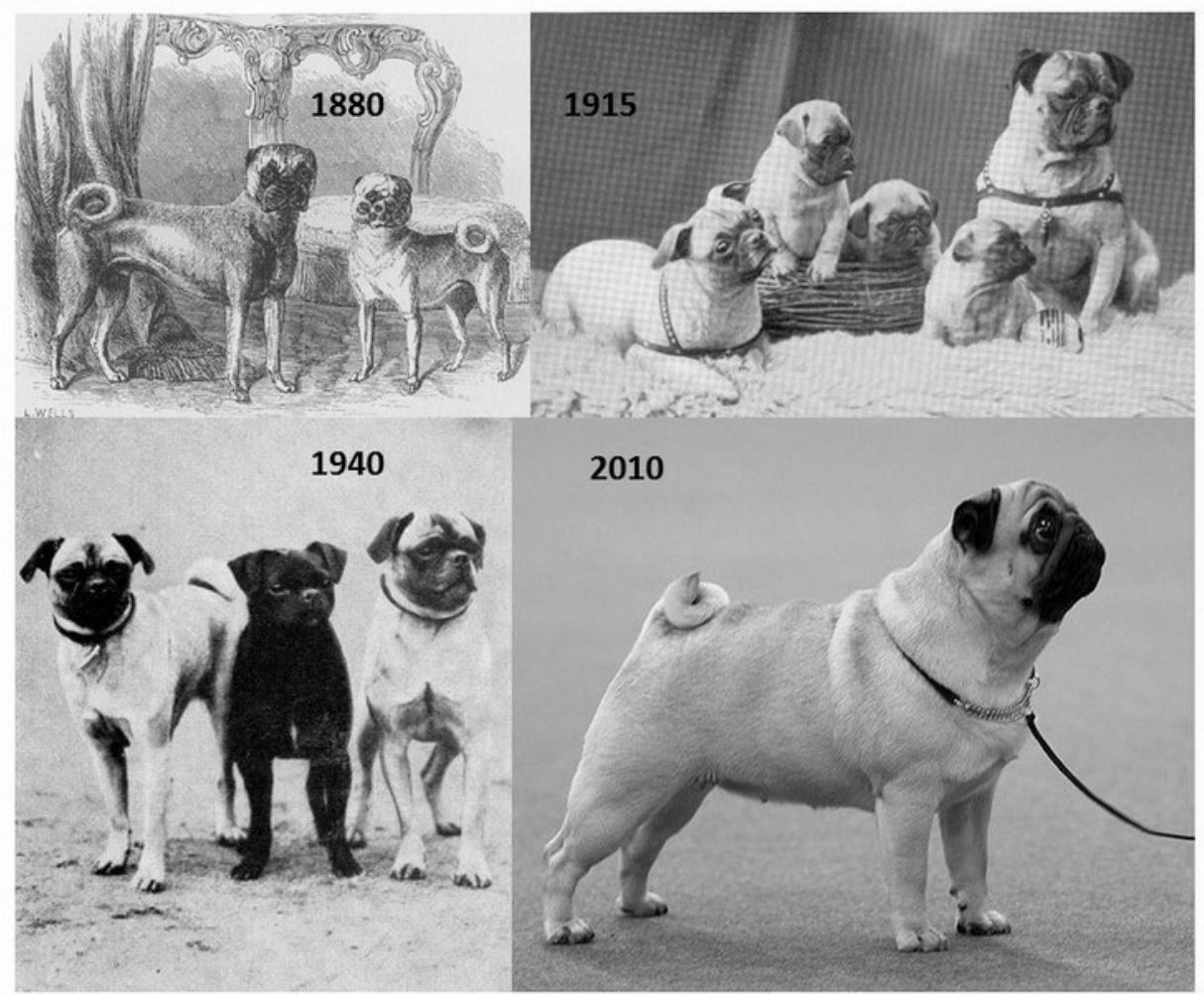


percent of the recognized breeds by the Fédération Cynologique Internationale (FCI) are hunting dogs. Among them we are aware of 35 pointing dog breeds and 65 scent dog breeds. In the 19th century, huntsmen started hunting alone with modern guns. They needed a single all-purpose gun dog. Mostly ancient pointers, retrievers, and spaniels have been modified to fit to the new requirements. Later on some new dog breeds have been created by cross-breeding to produce a modern all-purpose police and working dog like the Dobermann pinscher or the German Shepard. The ancient companion dog breeds like Maltese, Pug, Blenheim Spaniel experienced a boom now being available not only for aristocratic ladies but also for urban citizens. Thus, in the end of the 19th century, breeders began to establish "new" breeds stemming from varieties of the original breeds. This, to boost their business especially concerning Bichons like the Maltese (aka Bolognaise, Havanese, Coton de Tuléar, Löwchen) or small terriers like the Scottish Terrier (aka West Highland White, Skye, Cairn Terrier).

In Victorian Britain, many breeds had lost their "old jobs" for several reasons. Some had gone extinct. The "Turnspit", a Dachshund-like but very strong dog, was designed and intentionally bred to run on a wheel, called the turnspit wheel, to turn meat over the fire, to power spinning wheels, pumps and bellows over hundreds of years. His Nickname was "the Underdog". He has become unemployed because of steam engines and electric motors. After hundreds of years he has gone extinct very fast. In North America, the same destiny befell other dog breeds as well. The indigenous Coast Salish peoples (BC, Canada) had a special woolly dog. His hair became yarn for particularly valuable blankets. Labor-intensive dog-hair weaving disappeared quickly after the introduction of machine made blankets by trading companies. Consequently, the woolly-dogs were reportedly extinct by the third quarter of the 19th century (Barsh et al. 2002).

The prohibition of dogfights with the "Cruelty to Animals Act 1835“ was - fortunately - the destruction of the last Bulldog jobs in the United Kingdom. Decades earlier, dog fighting had gone out of fashion. Bulldogs had a very high reputation because of their courage and braveness, and was addressed as the British national dog. For that reason, urban gentlemen were looking for a bulldog as companion dog. Clever entrepreneurs quickly recognized their opportunity. At least since 1825 breeders like Ben White and Bill George operated puppy mills to satisfy the big demand for the new pet Bulldog (Farman 2010). The Bulldog was the first breed that had been converted from a working dog to a pet dog. Later on, in 1873, it should become the very first breed of the Victorian era officially recognized by the recently established Kennel Club. We all know what deep modifications this exactly "standardized" breed had to suffer through, taking not only our modern breeding system. We all know what a modest future the new system has provided for the Bulldog (Jung 2011b). The Bulldog has been the very first, but not the only dog breed switching from a working to a companion or pet dog. Starting with the Bulldog in the 1820th over more than 150 years until today about 60 dog breeds basically changed their role that way. The Victorian era marks the dawn of companion and pet dog breeding as a business. However, that are less than one-third of totally recognized breeds by the AKC, the KC or the FCI. Until today, business people keep on trying to place working dog breeds as pet dogs to conquer a new profitable market. Even breeds like livestock guarding dogs, e.g. Kangals or Ovcharkas or high-end working dogs like Border Collies have been offered as pet dogs. Thus, many breeds have been splitted in a working and a show line to cover both markets. However, the majority of modern dog breeds still represent ancient working breeds, mostly used for hunting purposes.

The Victorian era was an era of standardization that began with the standardization of thread sizes to boost production and trade. Official stud books for horses were starting in the dawn of the 19th century. British horses had been exported worldwide. Some decades later British breed dogs followed up. Thus, dog breeds have been standardized and uniformed as well. The spread of railroads enabled dogs from distant regions to mate, homogenizing their appearance on a national scale (Russell 2018). This new breeding industry needed regulation and quality standards to improve business worldwide. Fanciers demanded breed standards for the preservation of the old working breeds, which had lost their original jobs. The Kennel Club (KC) was founded on 4 April 1873. Gradually, new guidelines were set. They are officially valid until 
today:

- Registration for each dog for unique identification

- Stud Books, closed or with appendix registries; Stud Books provide a record of results for all Championship Dog Shows

- Pedigree for each dog (certificate for "pure bred")

- Written Standards to establish a detailed image of the ideal appearance of each breed. "Breed standards still reflect the reasons why the breed came into being" (The Kennel Club 2018)

- Championship Dog Shows in which (mainly companion- not hunting/working-) dogs are rated for how well their appearance conforms to a standard

- $\quad$ Rating on the shows by independent judges

- Breeding Clubs for each breed joined to the Kennel Club

That is the theory. Standardization in the 19th century did not lead to unification in dog breeding and each breed has steadily changed its appearance more or less depending on fashions. Even the classification as breed sometimes seems to be arbitrary. As an example, 192 dog breeds are officially recognized by the American Kennel Club, 220 recognized by the $\mathrm{KC}$ and not less than 345 recognized by the FCI on a so-called "definitive basis" (2018). From 192 to 345 officially recognized breeds, that is quite a difference - and we mentioned only the three biggest international Kennel Clubs. That gives us another hint that the Victorian breeding culture does not fit to the functional, zoological and historical view on dog breeds nor to evolution nor to ecology (Figure 1).

In particular, the principle of purebred breeding does not fit into reality and has never done so. In theory, we have closed stud books. Even officially, we see open stud books or stud books with appendix registries. Unofficially it is normal to fresh up the blood of a kennel from time to time by inter-breeding with phenotypically similar specimen or those from other kennel clubs. In particular, after the Second World War, most companion and pet dog breeds had lost their breeding potential. There was a genetic bottleneck. Thus, most stud books have been opened for many years. The real purebred dog is an idealized image and in some cases simply a breeders marketing tale. For dogs' fitness that are good news. However, modern puppy mills are breeding their own way to gain maximal profit. The rules of Kennel Clubs do not matter. In Germany, two out of three breeding puppies are produced in such farms without any control. Especially young fanciers, buying their pups online, are not interested in basic breeding standards (Packer et al. 2017).

Nevertheless, we can clearly identify a dog breed by appearance, behaviour and its genetic fingerprint (vonHoldt et al. 2010; Parker et al. 2017). Given such a variety in appearance and behaviour, it is unlikely that several and well described dog types would have derived from uniform village dogs in just a few decades and until the official initiation of dog breeding in 1873 with dozens of modern breed standards to follow. Dogs seem to live with human as specialized breeds since ancient times. We have found evidence that dog breeds and intentional dog breeding have been a very deep-rooted part of human culture - This evidence dates back for about 200 years. In his pioneering work (1860, 1868, 1874) Charles Darwin does not leave room for any doubt that dogs are separated in breeds and that these breeds have an ancient even "wild" origin. He described many dog breeds with an in each and classified them according to their different and clearly distinct behaviour including what he called "domestic instincts", e.g. pointers, retrievers, shepherds (1860, p. 213). Darwin assumed that "of another breed for another purpose; when we compare dog breeds, each breed seems to serve a purpose for humans in very different ways." (1860, p. 34) and "No instance is on record of such dogs as bloodhounds, spaniels, true greyhounds having been kept by savages: they are the product of long-continued civilization." Darwin dedicates a separate chapter related to the question of "Differences between the several Breeds of the Dog." (1868, p. 33) 
The Victorian era has set a caesura for numerous dog breeds. The focus was transferred from appearance towards of behaviour and fitness. The novel focus focused on "dog fashion" instead of dogs fitting to provide certain jobs. Consequently, dog entrepreneurs introduced several policies pertinent to pedigree dog breeding, including dog shows. The Victorian era primarily provided a framework for pet dog breeding as an upcoming international business - not more. Quite all dog breeds have reliable roots in ancient times. Many - but not the majority - of dog breeds have been switched over a time window from 1825 (Bulldog) until today (e.g. Australian shepherd) from working to pet dogs.

Regulations taking place in Victorian Britain were the beginning of nationwide dog breeding policies, in particular for dog shows (Russell 2018). Nevertheless, it was not the dawn of the supported breeds. Fashion dog breeding guidelines just adopted ancient dog breeding practices to the new requirements in modern human society and economy, their new ecological niche. Only a few new breeds have been created until now. It is likely, that most breeds have been modified and every so often gave rise to several "new" breeds. That is the nature of breeds - not only concerning dogs. Breeds are made for and by humankind. All breeds - horses, sheep, grains, cabbages or dogs - are designed for special purposes in special environments, climates and ecologies. Purposes and ecologies are steadily evolving; thus breeds steadily adapted to new requirements. While some dog breeds adapted, some breeds became extinct (Turnspit, Woolly Dog), some were modified (Bulldog), some were created new (German shepherd), some were reinvented (Hovaward) and some were recreated (Irish wolfhound). Given the above, we have evidence for highly heritable and functionally relevant breed differences in dog behaviour (McLean et al. 2019). For example, The Victorian era of dog breeding simply introduced new policies to adapt classical intentional dog breeding to modern business purposes. Nevertheless, even and in particular, under the policies of the Victorian breeding culture like official standards, show-judges and stud books, dog breeds have been modified steadily. If we look only at what has been bred entirely under the rules of the British Kennel Club, we have to realize that many pet dog breeds have changed their appearance and their behaviour dramatically e.g. pug, bulldog, basset hound, German shepard and are still changing until now (Fig. 1).

\section{Conclusion and Discussion}

We present evidence related to dog breeds, their origin and evolution long before the Victorian era began. We also present data pertinent to intentional dog breeding dating back for at least 2,400 years (Brewer et al. 2001). Dog breeds evolved and were later purposefully bred to perform and optimally various tasks as ordered by man. Hunting, guarding, sledding and herding are thought to be the earliest dog jobs. Even to serve simply as a pet is an ancient purpose. The separation in breeds or races is a need and a fundamental mark for the dog as a human working companion and partner (Jung and Pörtl 2018). Humans desired and thus bred a specialist for each job even for the job as pet. Cultures and technologies developed, as a consequence jobs carried out by working dogs did so as well. We may understand $\operatorname{dog}$ breeds as a reflection of human cultural evolution and history. Possibly, we may address it as a form of coevolution (Russel 2018; Schleidt and Shalter 2003, 2018). Darwin referred to this process as "coadaptation" (1860, p. 31). However, dog breeds are not and have never been set in stone (Russel 2018). In particular the so called pure bred dogs under the kennel clubs like KC, AKC and FCI are changing their appearance steadily and sometimes fundamentally especially in the last decades. Comparing the official show champions and the "Best of Breed" winners from 1970, 1990 and 2010 the differences are astonishing. If the traits of a breed change, it does not mean that it is a new breed now.

Humankind has formed every breed for its own purposes. This dates back to prehistoric times including plants or animals. Formerly, we have had dozens of clearly different tomato breeds for taste, climate, usage. Therefore, we did not need the European Union bureaucracy with its standardization and tomato specifications filling pages. Nevertheless, today only very few and selected new EU tomato breeds are officially recognized in Europe. The same is valid for dogs. Not kennel clubs invented breeds but breeds "invented and shaped" clubs. Dogs as breeds have not been invented in Victorian Britain. Breeds did not derive during decades from village dogs. Victorian 
breeding simply standardized dog breeds by appearance. Even dog breed standardization was much older and was not invented at that time (Xenophon 2017; Klemettilä 2015). Only the criteria, the scope and the methods were and have changed.

In former times - and regarding working dogs until today - primarily traits, behaviour and fitness were the leading features of each breed. In ancient times, breed standards had not been set up by

\section{References}

Aristotle 2011. Historia Animalium. Cambridge: Cambridge Classical Texts and Commentaries.

Barsh R. L., Jones J. M. \& Suttles W. 2002. History, ethnography, and archaeology of the Coast Salish woolly-dog. In L. M. Snyder and E. A. Moore (Eds.), Dogs and People in Social, Working, Economic or Symbolic Interaction (pp. 1-11). Oxford: Oxford Books.

Botigué L. R., Song, S., Scheu A., Gopalan S., Pendleton, A., Oetjens, M., Taravella, A., Seregély, T., Zeeb-Lanz, A., Arbogast, R., Bobo, D., Daly K., Unterländer M., Burger, J., Kidd, J., Veeramah, K. 2017. Ancient European dog genomes reveal continuity since the Early Neolithic. Nat. Commun. 816082.

Brewer D. et al., 2001. Dogs in Antiquity. Anubis to Cerberus. The origins of the domestic dog. Warminster: Aris \& Phillips.

Caius, J. 2018. De Canibus Britannicis. Reprint Outlook Verlag.

Comte de Buffon. 2009. Histoire Naturelle. Reprint Komet.

Coppinger, R. P., Coppinger, L. 2001. Dogs: a new understanding of canine origin, behavior and evolution. Chicago: University of Chicago Press.

Coppinger, R. P., Coppinger, L. 2016. What is a Dog? Chicago: University of Chicago Press.

Coulson, D., Campbell, A. 2001. African Rock Art: Paintings and Engravings on Stone New York: Harry N
Abrams.

Cuvier, G. 2012. Animal Kingdom. Reprint Forgotten Books.

Darwin, C. R. 1860. On the origin of species by means of natural selection, or the preservation of favoured races in the struggle for life. London: John Murray 2nd edition.

Darwin, C. R. 1868. The variation of animals and plants under domestication. London: John Murray.

Darwin, C. R. 1874. The descent of man, and selection in relation to sex. London: John Murray 2nd edition.

Farman, E. 2010. The Bulldog - A Monograph. Vintage Reprint Dog Books.

Fitzinger, L. J. 2017. Der Hund und seine Rassen: Naturgeschichte des zahmen Hundes, seiner Formen, Rassen und Kreuzungen. Norderstedt: Reprint Verlag Der Wissenschaften.

Germonpré, M., Láznicková-Galetová, M., Sablin, M.V., Bocherens, H. 2018. Self-domestication or human control? The Upper Palaeolithic domestication of the dog. In Vigne, J.D., Stépanoff, C. (eds), Rethinking domestication: Biosocial Approaches to hybrid communities. London: Routledge.

Gessner, K. 2008. Von den Hunden und dem Wolf. Stuttgart: edition tieger.

Guagnin, M., Perri, A., Petraglia, M. 2018. Pre-Neolithic evidence for dog-assisted hunting strategies in Arabia $J$ of Anthropological Archaeology 49 225-236.

Hekman, J. 2018. What is a dog breed? Accessed Dec 12, 2018, https://darwinsark.org/what-is-a-dog-breed/.

Holl, A. 2004. Saharan Rock Art, Archaeology of Tassilian Pastoralist Icongraphy AltaMira. Oxford: Press Walnut Creek.

Janssen, R., Janssen J. 1999. Egyptian Household Animals. Shire Publications.

Jung, C. 2011a. Rassehund am Ende? Norderstedt: BoD. 
Jung, C. 2011b. Bulldogs in Geschichte und Gegenwart. Daun: Kynos.

Jung, C., Pörtl, D. 2018. Scavenging Hypothesis: Lack of evidence for Dog Domestication on the Waste Dump. Dog Behavior Vol 4, No 2.

Klemettilä H., 2015. Animals and Hunters in the Late Middle Ages. Evidence from the BnF MS fr. 616 of the Livre de chasse by Gaston Fébus. New York: Routledge.

Lex Baiuvariorum 2016. Reprint EOD Network.

Lord, K., Feinstein, M., Smith, B., Coppinger, R. P. 2013. Variation in reproductive traits of members of the genus Canis with special attention to the domestic dog (Canis familiaris). Behavioural Processes 92, 131-142.

MacLean, E., Snyder-Mackler, N., vonHoldt, B., Serpell, J. 2019. Highly Heritable and Functionally Relevant Breed Differences in Dog Behavior. biorxiv preprint doi: https://doi.org/10.1101/509315

Oppian. 2012. On hunting Kynegetiká in Oppian's Cynegeticks. Reprint Gale ECCO.

Packer, R. M. A., Murphy, D., Farnworth, M. J. 2017. Purchasing popular purebreds: Investigating the influence of breed-Type on the pre-purchase motivations and behaviour of dog owners. Animal welfare 26 191-201.
Parker, H. G., Dreger, D.L., Rimbault, M., Davis, B.W., Mullen, A.B., Carpintero-Ramirez, G., Ostrander, E.A. 2017. Genomic Analyses Reveal the Influence of Geographic Origin, Migration, and Hybridization on Modern Dog Breed Development. Cell Rep. 25;19(4):697708 .

Perri, A. 2016. Hunting dogs as environmental adaptations in Jomon Japan. Antiquity 90 1166-1180.

Pitulko, V., Kasparov, A. 2017. Archaeological dogs from the Early Holocene Zhokhov site in the Eastern Siberian Arctic. J of Archaeological Science: Reports 13 491515.

Pörtl, D., Jung, C. 2017. Is dog domestication due to epigenetic modulation in brain? Dog Behavior Vol 3 No 2.

Richardson, H.D. 2018. Dogs. Reprint HardPress.

Russell, E. 2018. Greyhound Nation: A Coevolutionary History of England, 1200-1900. Cambridge: Cambridge University Press.

Schleidt, W. M., Shalter, M. D. 2003. Co-evolution of humans and canids: An alternative view of dog domestication: Homo Homini Lipus? Evolution and Cognition 9(1): 57-72.

\section{(c) creative}

This paper has been published by

Pet Behaviour Science

under a Creative Commons license 4.0 Non-comercial - Share Alike - Attribution

As an open access journal, it is free of charges for both authors and readers

www.petbehaviourscience.org 